San Jose State University

SJSU ScholarWorks

Master's Projects

Master's Theses and Graduate Research

5-1-2009

\title{
The Use of Complementary and Alternative Medicine for \\ Menopausal Symptoms among Chinese-American Women
}

Rebecca Kwai-Ying Chung

San Jose State University

Follow this and additional works at: https://scholarworks.sjsu.edu/etd_projects

Part of the Family Practice Nursing Commons

\section{Recommended Citation}

Chung, Rebecca Kwai-Ying, "The Use of Complementary and Alternative Medicine for Menopausal

Symptoms among Chinese-American Women" (2009). Master's Projects. 752.

DOI: https://doi.org/10.31979/etd.49ju-jb7m

https://scholarworks.sjsu.edu/etd_projects/752

This Master's Project is brought to you for free and open access by the Master's Theses and Graduate Research at SJSU ScholarWorks. It has been accepted for inclusion in Master's Projects by an authorized administrator of SJSU ScholarWorks. For more information, please contact scholarworks@sjsu.edu. 


\section{SAN JOSE STATE UNIVERSITY SCHOOL OF NURSING}

\section{MASTER'S PROGRAM PROJECT OPTION (PLAN B) PROJECT SIGNATURE FORM}

STUDENT NAME

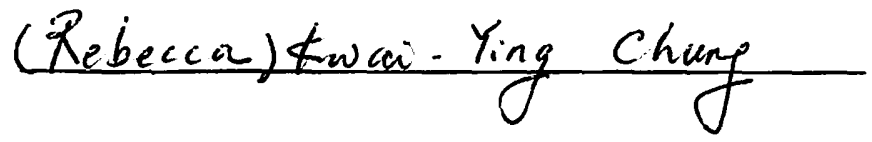

SEMESTER ENROLLED 2009 Spring TITLE OF PROJECT The use of complementary and alternative medicine for menopausal symptoms

among Chinese-American Women NAME OF JOURNAL Social Science and Medicine

The project and the manuscript have been successfully completed and meet the standards of the School of Nursing University. The project demonstrates the application of professional knowledge, clinical expertise, and scholarly thinking. An abstract of the project and two copies of the manuscript are attached.

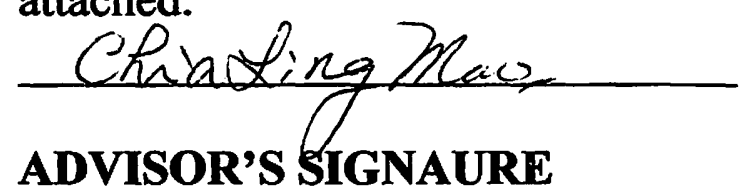

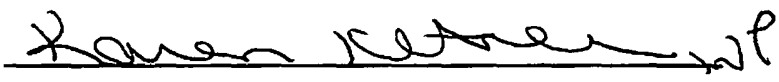

ADVISOR'S SIGNAURE

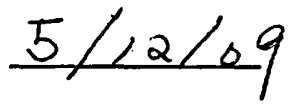

DATE

$$
5-12-09
$$

DATE

Please submit the form to the Graduate Coordinator. Attach abstract, two copies of the manuscript, and the documentation of submission to the journal (i.e., postal receipt or email). 
The Use of Complementary and Alternative Medicine for Menopausal Symptoms among Chinese-American Women

Rebecca Kwai-Ying Chung, MSN, FNP Student First advisor: Dr. Chia-Ling Mao, Associate Professor Second Advisor: Karen Ketner, Co-Director of FNP program and Lecturer May 14, 2009.

\begin{abstract}
The objectives of this research were to study the use of complementary and alternative medicine (CAM) for menopausal symptoms among Chinese-American women, and to examine the correlation between CAM use, acculturation, and CAM insurance coverage. The study revealed that Chinese-American women experience menopausal symptoms even when they still have regular menstrual cycles. Early education on women's health, especially about menopause, is recommended. A significant correlation was found between the women being asked by their health care providers regarding CAM use, and open discussion regarding the women's CAM use with their health care providers $(p<0.05)$. The researchers suggest that health care providers ask their patients about their CAM use in order to encourage open discussion of CAM use with their patients.
\end{abstract}

Key words: Menopausal symptoms; Acculturation; Complementary and Alternative medicine. 


\title{
Running head: CAM USE AMONG CHINESE-AMERICAN WOMEN
}

The Use of Complementary and Alternative Medicine for Menopausal Symptoms among Chinese-American Women

\author{
Rebecca Kwai-Ying Chung, RN, MSN \\ Chia-Ling Mao, Ph.D. RN-BC \\ Associate Professor \\ Karen Ketner, MSN, FNP, RN \\ Co-Director of FNP program and Lecturer \\ School of Nursing, San Jose State University
}




\begin{abstract}
The objectives of this research were to study the use of complementary and alternative medicine (CAM) for menopausal symptoms among Chinese-American women, and to examine the correlation between CAM use, acculturation, and CAM insurance coverage. The study revealed that Chinese-American women experience menopausal symptoms even when they still have regular menstrual cycles. Early education on women's health, especially about menopause, is recommended. A significant correlation was found between the women being asked by their health care providers regarding CAM use, and open discussion regarding the women's CAM use with their health care providers $(p<0.05)$. The researchers suggest that health care providers ask their patients about their CAM use in order to encourage open discussion of CAM use with their patients.
\end{abstract}

Key words: Menopausal symptoms; Acculturation; Complementary and Alternative medicine. 
The Use of Complementary and Alternative Medicine for Menopausal Symptoms among

\section{Chinese-American Women}

The use of complementary and alternative medicine (CAM) among women is very common. According to a National Health Interview Survey conducted in 2002, approximately $40 \%$ of women had used some kind of complementary and alternative medicine (CAM) during the previous year (Upchurch et al., 2007). Furthermore, many studies have shown that CAM is helpful in treating women's menopausal symptoms (Canter \& Kwee, 2008; Ma, Drieling, \& Stafford, 2006; van der Sluijs, Bensoussan, Liyanage, \& Shah, 2007; Yan, Liu, Liu, \& Zhao, 2008)

The benefits of CAM for menopausal symptoms are especially significant for women because hormone replacement therapy (HRT), one of the conventional treatments for menopausal symptoms, has been found to cause severe side effects such as stroke, thromboembolic events, breast cancer (with five or more years of use), and cholecystitis (Nelson, Humphrey, Nygren, Teutsch, \& Allan, 2002). Even before the negative effects of HRT were noticed, studies found that most of the women preferred CAM use to HRT (Newton, Buist, Keenan, Anderson, \& LaCroix, 2002).

In previous studies, acculturation was found to be a factor in the health behavioral changes among immigrants in the USA (Hsiao et al., 2006; Kandula et al., 2008). One recent study showed that acculturation was positively associated with the use of CAM among immigrants (Su, Li, \& Pagán, 2008). However, another study done by Hsiao, Wong, Goldstein, Becerra, Cheng \& Wenger (2006) regarding the relationship between acculturation and CAM use in Asian-American subgroups, including both men and women, indicated that less English proficiency was associated with greater CAM use by 
Chinese-Americans. In contrast, the study found that less English proficiency was associated with less CAM use by South Asians. Does the level of acculturation affect

Chinese-American women's CAM use for their menopausal symptoms?

Other studies showed that the availability of CAM insurance was associated with CAM use among Americans (Lafferty et al., 2006; Shih, Lew-Ting, Chang, \& Kuo, 2008). Is CAM insurance associated with CAM use among Chinese-American women?

\section{Research Purpose}

The purposes of this study are (a) to exam the prevalence and types of CAM used by Chinese-American women around their age of menopause, and (b) to examine if level of acculturation and CAM insurance coverage affect the use of CAM among ChineseAmerican women.

The following four research questions guided the study:

1. Do Chinese-American women use CAM for their menopausal symptoms?

2. What is the type of CAM used most frequently by Chinese-American women?

3. What are their main purposes of using CAM?

4. Does level of acculturation and CAM insurance coverage affect the use of CAM among Chinese-American women?

\section{Literature Reviews}

\section{CAM Use among Women}

Upchurch et al (2007) had conducted a National Health Interview Survey (NHIS) to obtain a national profile of women CAM users in the USA. The survey was done in person by conducting household interviews with the use of specific questionnaires. A total of 17,295 women were interviewed. The researchers found that 
about $40 \%$ of women had recent CAM use. The most frequently used forms of CAM were biologically based therapies $(23.8 \%)$, followed by mind-body therapies $(20.9 \%)$.

\section{CAM Use for Menopausal Symptoms}

In 2006, Ma, Drieling \& Stafford conducted an online national survey to find out how women use alternative therapies for their menopausal symptoms. They obtained data from 781 US women from 40 to 60 years of age. According to their findings, $37 \%$ of the women surveyed had used hormone therapy (HT), but $59 \%$ of them had stopped using HRT due to the possible health risks. Thirty-one percent of the women used herbal products and $41 \%$ still used them continuously. Among these herb users, $44 \%$ experienced therapeutic effects from using herbs (Ma et al., 2006). The authors concluded that CAM was becoming popular for the relief of menopausal symptoms.

Similar CAM use findings were seen in other countries. Green, Denham, Ingram, Hawkey and Greenwood (2007) conducted a prospective, randomized, controlled pilot trial in a clinic setting in the United Kingdom. They wanted to examine if professional herbal practice was effective for the treatment of menopausal symptoms. Participants were divided into a treatment group $(n=15)$, which received treatment from herbal practitioners, and a control group $(n=30)$, which didn't get treatment until four months later. The herbal practitioners provided participants with six consultations consisting of discussions regarding nutrition, lifestyle, and herbal prescriptions. This study showed that the treatment package provided by herbal practitioners significantly reduced menopausal symptoms such as hot flushes and low libido significantly (Fugh-Berman \& Green, 2008). 
In 2007, van der Sluijs, Bensoussan, Liyanage, \& Shah conducted a survey on 1,296 women in Sydney, Australia to find out the extent of CAM use for their menopausal symptoms. The survey showed that $53.8 \%$ of the participants had either visited a CAM practitioner or used a CAM product in the last 12 months. This study showed that the CAM users rated massage, chiropractic, and nutrition as the most effective therapies. According to these CAM users, the most effective products were phytoestrogen tablets, evening primrose oil, and black cohosh (van der Sluijs et al., 2007).

Previous studies of ethnic women's patterns of CAM use showed that different ethnic groups had different rates of using CAM (Bair et al., 2008; Kronenberg, Cushman, Wade, Kalmuss, \& Chao, 2006). Bair et al. (2008) and Kronenberg et al. (2006) found that the rate of CAM use was higher among White women than among the other ethnic groups. Chinese women used less CAM than White and Japanese women, but used more CAM than African-American and Hispanic women. There was no explanation for the differences of CAM use among the different ethnic groups. Acculturation and CAM Use

In 2006, Hsiao, Wong, Goldstein, Becerra, Cheng \& Wenger examined if acculturation could be a predictor of CAM use in the Asian-American subgroups including Chinese-Americans, Filipino-Americans, Japanese-Americans, South Asians, Asian Pacific Islanders, and non-Hispanic whites. They hypothesized that less acculturation was associated with increased CAM use. They collected data by doing a cross-sectional survey of a sample of 9,187 adults living in California. With the data collected, the researchers tried to correlate the use of CAM and the factors of 
acculturation, which were English proficiency and length of stay in the USA. The researchers stated that they could not find any correlation between acculturation and CAM use for most Asian-American subgroups. However, they did find that acculturation had opposite effects among the Asian-American subgroups, limited English proficiency was associated with greater CAM use by Chinese-Americans, but with less CAM use by South Asians. The researchers stated that they could not explain why English proficiency had different effects on Chinese-Americans and South Asians.

One recent study showed that the level of acculturation was strongly associated with the use of CAM among immigrants (Su et al., 2008). The researchers analyzed the data from a CAM supplement to the 2002 National Interview Survey and found that immigrants used less CAM than native-born Americans, but the rate of CAM use increased with the level of acculturation (Su et al., 2008).

Association between CAM insurance and CAM use

Additionally, insurance coverage may be another factor for choosing CAM. Some types of CAM, such as chiropractic, acupuncture and massage may be covered by health insurance. Cleary-Guida, Okvat, Oz, \& Ting (2001) studied the extent of health insurance coverage for CAM within the region of New York, New Jersey, and Connecticut in the USA. They found that all of the insurance carriers in the survey covered chiropractic, 17 out of 43 (39.5\%) of the insurance companies covered acupuncture, and 16 (37.2\%) insurance companies cover massage therapy. However, even though consumers were willing to pay out of pocket for CAM if they believed CAM provided health benefits, consumers wanted broader CAM insurance coverage from their insurance providers (Cleary-Guida, Okvat, Oz, \& Ting, 2001). 
On the other hand, the availability of CAM insurance may affect CAM use. Lafferty et al. (2006) found that greater CAM insurance coverage was associated with greater utilization of CAM. In another study of the determinants of CAM use by Hendrickson, Zollinger and McCleary (2006), a strong correlation between insurance coverage for CAM and CAM use was noted (Hendrickson, Zollinger, \& McCleary, 2006).

\section{Menopause Status \& Menopausal Symptoms}

According to previous studies, menopause status included premenopausal, perimenopausal and postmenopausal status (Bair et al., 2008; Deecher \& Dorries, 2007; Kronenberg et al., 2006). Premenopause was defined as having had regular menstrual periods within the past three months. Perimenopausal women were those who still had menstrual periods but whose periods were irregular during the past twelve months. Postmenopausal status referred to having no menstrual period for more than twelve months. Menopausal symptoms can be categorized as vasomotor, somatic, and psychological symptoms (Bair et al., 2008; Gold et al., 2006). Vasomotor symptoms include hot flashes, night sweats, or cold sweats. Somatic symptoms include stiffness or aches in the joints, or headaches. Psychological symptoms consist of feeling blue, mood swings, irritability, and nervousness. Women are defined as symptomatic if they experienced any of the vasomotor symptoms in the past one month, or experienced any of the somatic or psychological symptoms more than six days in the past two weeks (Bair et al., 2008). Vasomotor symptoms are the most common menopausal symptoms; they occur most often during the perimenopausal period and continue to the postmenopausal period (Deecher \& Dorries, 2007; Gold et al., 2006). 


\section{Methodology}

Research Design

This study employed a non-experimental, cross-sectional research design. Data were collected through self-administered surveys. Those women who were interested in the research and were self-identified as meeting the research requirements (ChineseAmerican women who were either premenopausal, perimenopausal or menopausal) were invited to participate in the survey. Open invitation was extended through different networks including co-workers, friends, church members, neighbors or other persons from social connections. Snowballing was used for subject recruitment. A total of 60 questionnaires were distributed to participants and 50 were returned, with a return rate of $83.3 \%$.

\section{Survey Instrument}

The survey tool consisted of a questionnaire containing four parts. The first part included socio-demographic data such as health insurance and its coverage for CAM, age, place of birth, and years of stay in the USA.

The second part contained questions about menopausal status and symptoms, based on the questionnaire from the Study of Women's Health across the Nation (SWAN) (SWAN, 2002). The menopausal status and symptoms were based on the women's self-reports of their menstrual periods and symptoms.

The third part contained questions regarding levels of acculturation. Acculturation level was based on the validated acculturation scale used by Gupta, Kumar \& Stewart (2002) in their study of the association between acculturation and cervical cancer screening among South Asian women in Canada (Gupta, Kumar, \& 
Stewart, 2002). This questionnaire consisted of six questions. A score was assigned to each answer to the six questions. The scores ranged from 6 to 20 and a higher score indicated a higher level of acculturation. The scores were further categorized into three levels. Scores from 6-10 were categorized as level 1, 11-15 were level 2, and 16 to 20 were level 3. To use this scale for Chinese-American women in this project, the word "Canadian" was replaced with "American," and the words "South Asian" were replaced with "Chinese-American."

The fourth part concerned the use of CAM based on the questionnaire from SWAN. This tool had been used by SWAN in assessing the use of CAM among women across the nation (Bair et al., 2005; Bair et al., 2008; Kronenberg et al., 2006). The CAM list included four major types of CAM. The first type consisted of physical methods such as massage, acupressure, exercise, bodywork and acupuncture. The second type comprised psychological methods including meditation, mental imagery, and relaxation techniques. The third type of CAM was special diets or nutritional remedies such as macrobiotic or vegetarian diets, vitamins, and supplements. The fourth type of CAM consisted of herbs or herbal remedies such as homeopathy, Chinese herbs or teas, and traditional Chinese medicine (Bair et al., 2008). Women were asked about the types of CAM they had used in the past 12 months and the reasons for using them. The use of CAM was defined as the use of any CAM in the past 12 months. Participants were also asked about communication with their health care providers regarding their use of CAM.

The first, second and third parts of the questionnaire were translated into Chinese by the researcher, a certified medical translator herself. A Chinese-American scholar and teacher at San Jose University verified the researcher's translation. The fourth part of the 
questionnaire was a Chinese version of questions from SWAM, which did not require translation.

Data Analysis

Data was analyzed using MS excel and SPSS 13.0 for Windows. Data regarding CAM use was grouped into physical methods, psychological methods, nutritional remedies and herbal remedies. Descriptive statistics of sociodemographic data and CAM use were performed by SPSS. Correlation between categorical variables was analyzed with Chi-Square and continuous variables with bivariate analyses or linear regression. Statistical significance was set, $\mathrm{p}<0.05$.

\section{Results}

\section{Sociodemographic Data}

Among the 50 women surveyed, most of them were 51 to 55 years of age (44\%) (see Table 1). All of the participants were born outside of the USA; five participants did not name their place of birth. The other 45 women were immigrants from China (38\%), Hong Kong (36\%), Taiwan (10\%), and Malaysia (6\%). All participants identified themselves as Chinese-American and most of them have been living in the USA for more than 20 years $(56.3 \%)$ (see Table 1$).$

\section{Health Insurance}

Most of the subjects $(n=45,90 \%)$ had health insurance, but only $19(42 \%)$ had insurance coverage for CAM. In another words, only 19 subjects had CAM insurance and 31had no CAM insurance (see Table 1).

Menopausal Status and Menopausal Symptoms 
Among the 50 subjects, eight (16\%) were premenopausal, nine (18\%) were perimenopausal, and $33(66 \%)$ were menopausal. Among the eight premenopausal women, two (25\%) already had menopausal symptoms. Five out of nine of the perimenopausal women (55.6\%) had menopausal symptoms, and 16 out of $33(48.5 \%)$ of the menopausal women had menopausal symptoms (see Table 1). The total number of symptomatic women was 23 out of $50(46 \%)$.

The overall major menopausal symptoms among the Chinese-American women were vasomotor symptoms (see Table 1), which were experienced most frequently during the perimenopausal period (see Table 2). This finding was similar to the findings in other studies (Deecher \& Dorries, 2007; Gold et al., 2006).

\section{The Prevalence of CAM Use}

The majority of the subjects used CAM; 43 (86\%) report using CAM. Among the 43 CAM users, two (5\%) used only one type of CAM, and 41 women (95\%) used more than one type of CAM. All four major types of CAM (physical methods, psychological methods, nutritional remedies, and herbal remedies) were commonly used by the subjects. However, nutritional remedies were found to be the most popular type of CAM $(n=39,90.7 \%)$. Psychological methods were used less frequently than the other three types of CAM ( $n=22,51 \%)$ (see Table 3$)$.

The Prevalence of the Different Types of CAM

The prevalence of different types of nutritional remedies.

Twenty-two participants were using at least one type of nutritional remedy. The most frequently used nutrient was calcium $(n=30)$. The other nutritional remedies were multivitamin $(n=25)$, vitamin $C(n=10)$, vitamin $E(n=10)$, vitamin $D(n=10)$, vegetarian 
$\operatorname{diet}(n=6)$, vitamin $A(n=5)$, vitamin $B(n=5)$, magnesium $(n=4)$, zinc $(n=3)$, megavitamin therapy $(n=2)$, other vitamin $(n=2)$, boron $(n=1)$, copper $(n=1)$, other minerals $(n=1)$, glucosamine $(n=1)$, and omega $3(n=1)$ (see Table 3$)$.

The prevalence of different types of herbal remedies.

Thirty-one (62\%) of the participants reported using at least one type of herbal remedy. The herbal remedy most frequently used was American ginseng $(n=23)$. The other types of herbal remedies used included dong quai $(n=10)$, chuan xiang $(n=9)$, ginseng $(n=7)$, fu ling $(n=8)$, he shou wu $(n=5)$, other Chinese herbs $(n=5)$, Siberian ginseng $(n=2)$, black cohosh $(n=2)$, chamomile $(n=2)$, motherwort $(n=2)$, bee pollen $(n=2)$, evening primrose $(n=1)$, ze xie $(n=1)$, other herbs $(n=1)$, Chinese patent formulas $(n=1)$, and Promensil $(n=1)$ (see Table 3).

The prevalence of different types of physical methods.

Twenty-five participants were using at least one physical method of CAM. The most common types of physical methods used were massage $(n=10)$ and bodywork $(n=10)$. The other methods used were acupressure $(n=9)$, Tai Chi $(n=9)$, aerobics $(n=9)$, yoga $(n=6)$, Chi Kong $(n=4)$ and yoga $(n=6)$ (see Table 3).

The prevalence of different types of psychological methods.

Twenty-two participants were using at least one type of psychological method of CAM. The most common psychological method used was Prayer $(n=20)$. The others included prayer's group $(n=11)$, relaxation techniques $(n=6)$, women's health group $(n=4)$, hypnosis $(n=4)$, others $(n=3)$, meditation $(n=2)$, aromatherapy $(n=1)$, self-help group $(n=1)$, and visualization/imagery $(n=1)($ See Table 3$)$.

Correlation between CAM Insurance and CAM Use. 
Among the survey participants who had CAM insurance $(n=19)$, the rate of CAM use was $84 \%$. Among the participants without CAM insurance $(n=31)$, the rate of CAM use was $87 \%$. The result of Chi-square showed that CAM insurance and CAM use were not significantly related, $X^{2}(1, \mathrm{~N}=50)=0.82, \mathrm{p}=0.775$.

Acculturation Score

The acculturation scores of the participants ranged from 8 to 17 . The mean score was 12.22 with SD 2.36. The scores were categorized into 3 levels: Level 1(score 5-10), Level 2 (score 11-15), and Level 3 (score 16-20). More than half of the participants were in acculturation Level two $(64 \%, n=32)$, with $24 \%(n=12)$ participants in Level 1 , and 12 $\%(n=6)$ in Level 3 (see Table 1).

Correlation between acculturation score and the use of CAM.

The percentages of CAM use in relation to the different acculturation scores were analyzed by descriptive statistics (see Table 4). Correlation between CAM use and acculturation score was analyzed with bivariate analyses. Acculturation scores and CAM use were not significantly related, $r(7)=-0.224, p=0.562$.

Correlation between acculturation and multiple use of CAM.

The majority of women used more than one type of CAM. However, there was no correlation between the acculturation score and the multiple use of CAM, $r(6)=0.034$, $\mathrm{p}=0.814, \mathrm{p}>0.05$.

Acculturation levels and length of stay in the USA.

A one-way ANOVA was used to analyze the effect of length of stay in the USA on acculturation level. Length of stay in USA did not affect the acculturation level of the subjects, $\mathrm{F}(4,43)=0.955, \mathrm{p}>0.05$ 
Reasons For Using CAM

Among the 43 women who used CAM, 31 used CAM for general health maintenance, four used CAM for women's health, two used CAM for other reasons, one used CAM for menopausal symptoms, and one used CAM for menstrual symptoms (see Table 3). Four women did not mention their reasons for using CAM.

\section{Communications Between Health Care Providers and Participants}

Forty-two subjects (84\%) did not share their CAM use with their health care providers (HCPs). Only 16\% $(n=8)$ of the participants discussed their CAM use with their HCPs. On the other hand, $84 \%(n=42)$ of the participants replied that their HCPs had never asked about their CAM use Only $16 \%(n=8)$ of the participants had been asked about their CAM use by their HCPs.

The result of Chi-squre revealed that the subjects' sharing of their CAM use was significantly influenced by whether their HCPs asked about their CAM use or not, $x^{2}(1$, $\mathrm{N}=50)=28.537, \mathrm{p}<0.05$

\section{Discussion and Implications}

\section{Menopausal Status and Symptoms}

Menopausal symptoms may begin before the irregularity of menstrual cycle. The study showed that some of the women had menopausal symptoms during premenopausal period (see Table 1). Also, perimenopausal women experienced more menopausal symptoms than menopausal women (see Table 2). The most frequent symptoms experienced by the Chinese-American women were vasomotor symptoms. Based on the findings of this study, it is highly recommended to have early menopausal education for women. 


\section{CAM Use and CAM Insurance}

The majority (86\%) of the subjects used at least one type of CAM but only a small portion (38\%) had CAM insurance coverage. Further statistical analysis showed that CAM use did not significantly correlate with CAM insurance coverage $(\mathrm{p}=0.775)$; women choose to use CAM whether or not they have CAM insurance coverage. Health care providers (HCPs) need to be aware that Chinese-American women's use CAM is a common phenomenon. The HCPs should make it a routine to ask their clients about CAM use.

\section{CAM Use and Acculturation Levels}

Association between CAM use and acculturation levels was not found $(p=0.562)$ in this study. CAM use among Chinese-American women was not affected by their acculturation levels.

Prevalence of the Type of CAMUse

Nutritional remedies including multivitamins and calcium supplements were the most commonly used CAM. However, the regulation of dietary supplement is not as strict as it is for conventional drugs (National Institutes of Health, 2009). Therefore, CAM consumers need to be aware of the safety and quality of the dietary supplements they consume. Health care providers need to educate and alert their patients about the safety issues surrounding dietary supplements.

One type of CAM practiced by the Chinese-American women was Chinese medicine including acupuncture, Tai Chi, Chi Kong, and traditional Chinese herbs. . However, the subjects also used therapies beyond Chinese Medicine such as yoga, 
aerobics, American ginseng, motherwort, and evening primrose. This phenomenon indicates that Chinese-American women are adapting to American forms of CAM.

Herbs have been commonly accepted as safe agent since they are rooted in nature form. In fact, some of the herbs may have severe side effects and be hazardous to health with inappropriate use (Dobos et al., 2005; Tsai, 2007). For example, American ginseng, an herb frequently used to enhance immunity, may cause high blood pressure, insomnia, restlessness, anxiety, headache, breast pain and vaginal bleeding (University of Maryland Medical Center, 2009). Moreover, American ginseng may interact adversely with other drugs. American ginseng may increase the action of hypoglycemic agents, decrease the effectiveness of Warfarin, block the painkilling effects of morphine, and increase the effects of psychiatric medications (University of Maryland Medical Center, 2009a).

Dong quai, which is a traditional Chinese herbal medicine to treat dysmenorrhea, premenstrual syndrome (PMS) and menopausal symptoms, may increase the risk of miscarriage. Dong quai can also increase the effects of anticoagulants such as warfarin and cause bleeding (University of Maryland Medical Center, 2009b).

Both CAM consumers and health care providers need to be aware of the adverse effects of CAM. Also, it is strongly recommended by the National Center for Complementary and Alternative Medicine that patients should talk to their health care providers about their CAM use (National Institutes of Health, 2008).

\section{Reasons For CAM Use}

The majority (31 out of 43) of the subjects used CAM for general health maintenance and only one woman (1 out of 43) used CAM for menopausal problems (see Table 3). The aforementioned reasons for using CAM may be associated with the 
Chinese cultural health concept of Yin-Yang balance. In general, the Chinese people believe that the balance of Yin (female force) and Yang (the male force) is important to life and health (Stanford, 2001). Based on this belief, menopausal problems may be viewed as the result of the imbalance of Yin-Yang upon the body. Hence, the menopausal problem is not viewed as an isolated problem, but rather an integral part of general health. The enhancement of general health, which is the restoration of Yin-Yang balance by using CAM, is one of the major approaches used to solve health problems (Chen, Miaskowski, Dodd, \& Pantilat, 2008; Li, Stotts, \& Froelicher, 2007). This may be the reason why the majority of the Chinese-American women replied that they used CAM for general health rather than for an isolated problem. However, more studies regarding CAM beliefs and reasons for CAM use among Chinese-American women are needed.

Communication with Health Care Providers about CAM Use.

Most of the subjects (84\%) didn't talk about CAM with their health care providers (HCPs) while most of their HCPs (also 84\%) didn't ask about the women's CAM use, either. Communication between patients and their HCPs regarding CAM use seems to be very limited. Statistical analyzes showed that questioning of patients by their HCPs regarding their use of CAM correlated with discussion of CAM between HCPs and their patients $(\mathrm{p}<0.05)$. In other words, discussion of CAM use between patients and their HCPs is much more likely to occur when HCPs ask their patient about their use of CAM. Since herbal medicines may interact with other drugs and possibly cause harmful side effects to the body, HCPs should establish and encourage open discussion about CAM use among patients. 


\section{CAM use among Chinese-American women 19}

\section{Limitations}

This study recruited only subjects from the Santa Clara County in California, USA. Due to limited sample size and geographic area, the results of this study can only be applied to the population studied and can not be generalized to a larger population of Chinese-American women. Further studies need to be conducted with a larger randomly selected sample.

\section{Conclusion}

CAM use is poplar among Chinese-American women. It is not affected by individual's acculturation levels or CAM insurance coverage. The most commonly used CAM is nutritional remedy. The major purpose of CAM use is not for menopausal symptoms, but instead, for general health enhancement. Based on the findings of this study, it is highly recommended that health care providers actively approach their patients regarding their use of CAM, particularly in regards to the possible herb-to-drug interactions.

This study revealed that Chinese-American women may experience menopausal symptoms before they experience irregular menstrual cycles associated with menopause. Therefore early education on women's health especially about menopause is required. 


\section{References}

Bair, Y. A., Gold, E. B., Azari, R. A., Greendale, G., Sternfeld, B., Harkey, M. R., et al. (2005). Use of conventional and complementary health care during the transition to menopause: Longitudinal results from the study of women's health across the nation (SWAN). Menopause (10723714), 12(1), 31-39.

Bair, Y. A., Gold, E. B., Zhang, G., Rasor, N., Utts, J., Upchurch, D. M., et al. (2008). Use of complementary and alternative medicine during the menopause transition: Longitudinal results from the study of women's health across the nation. Menopause (New York, N.Y.), 15(1), 32-43.

Canter, P. H., \& Kwee, S. H. (2008). Chinese herbal medicine for menopausal symptoms. Focus on Alternative \& Complementary Therapies, 13(1), 20-22.

Chen, L., Miaskowski, C., Dodd, M., \& Pantilat, S. (2008). Concepts within the Chinese culture that influence the cancer pain experience. Cancer Nursing, 31(2), 103-108.

Cleary-Guida, M., Okvat, H. A., Oz, M. C., \& Ting, W. (2001). A regional survey of health insurance coverage for complementary and alternative medicine: Current status and future ramifications. Journal of Alternative \& Complementary Medicine, 7(3), 269-273.

Deecher, D. C., \& Dorries, K. (2007). Understanding the pathophysiology of vasomotor symptoms (hot flushes and night sweats) that occur in perimenopause, menopause, and postmenopause life stages. Archives of Women's Mental Health, 10(6), 247257.

Dobos, G. J., Tan, L., Cohen, M. H., McIntyre, M., Bauer, R., Li, X., et al. (2005). Are national quality standards for traditional Chinese herbal medicine sufficient? 
Current governmental regulations for traditional Chinese herbal medicine in certain western countries and China as the eastern origin country. Complementary Therapies in Medicine, 13(3), 183-190.

Fugh-Berman, A., \& Green, J. (2008). Herbalist treatment of menopausal symptoms. Focus on Alternative \& Complementary Therapies, 13(1), 19-20.

Green, J., Denham, A., Ingram, J., Hawkey, S. \& Greenwood, R. (2007). Treatment of menopausal symptoms by qualified herbal practitioners: a prospective randomized controlled trial. Family Practice, 24, 468-474.

Gold, E. B., Colvin, A., Avis, N., Bromberger, J., Greendale, G. A., Powell, L., et al. (2006). Longitudinal analysis of the association between vasomotor symptoms and race/ethnicity across the menopausal transition: Study of women's health across the nation. American Journal of Public Health, 96(7), 1226-1235.

Gupta, A., Kumar, A., \& Stewart, D. E. (2002). Cervical cancer screening among south Asian women in Canada: The role of education and acculturation. Health Care for Women International, 23(2), 123-134.

Hendrickson, D., Zollinger, B., \& McCleary, R. (2006). Determinants of the use of four categories of complementary and alternative medicine. Complementary Health Practice Review, 11(1), 3-26.

Hsiao, A., Wong, M. D., Goldstein, M. S., Becerra, L. S., Cheng, E. M., \& Wenger, N. S. (2006). Complementary and alternative medicine use among Asian-American subgroups: Prevalence, predictors, and lack of relationship to acculturation and access to conventional health care. Journal of Alternative \& Complementary Medicine, 12(10), 1003-1010. 
Kandula, N. R., Roux, A. V., Chan, C., Daviglus, M. L., Jackson, S. A., Ni, H., et al. (2008). Association of acculturation levels and prevalence of diabetes in the multi-ethnic study of atherosclerosis (MESA). Diabetes Care, 31(8), 1621-1628.

Kronenberg, F., Cushman, L. F., Wade, C. M., Kalmuss, D., \& Chao, M. T. (2006). Race/ethnicity and women's use of complementary and alternative medicine in the United States: Results of a national survey. American Journal of Public Health, 96(7), 1236-1242.

Lafferty, W. E., Tyree, P. T., Bellas, A. S., Watts, C. A., Lind, B. K., Sherman, K. J., et al. (2006). Insurance coverage and subsequent utilization of complementary and alternative medicine providers. American Journal of Managed Care, 12(7), 397 404.

Li, W., Stotts, N. A., \& Froelicher, E. S. (2007). Compliance with antihypertensive medication in Chinese immigrants: Cultural specific issues and theoretical application. Research \& Theory for Nursing Practice, 21(4), 236-254.

Ma, J., Drieling, R., \& Stafford, R. S. (2006). US women desire greater professional guidance on hormone and alternative therapies for menopause symptom management. Menopause (New York, N.Y.), 13(3), 506-516.

National Institutes of Health (February, 2009). Using Dietary Supplements Wisely. Retrieved on April 21, 2009 from http://nccam.nih.gov/health/supplements/wiseuse.htm\#fed National Institutes of Health (October, 2008). Tips for talking with your health care providers about CAM. Retrieved on April 21, 2009 from http://nccam.nih.gov/health/decisions/talkingaboutcam.htm\#reason 
Nelson, H. D., Humphrey, L. L., Nygren, P., Teutsch, S. M., \& Allan, J. D. (2002). Scientific review and clinical applications. postmenopausal hormone replacement therapy: Scientific review. JAMA: Journal of the American Medical Association, $288(7), 872-881$

Newton, K. M., Buist, D., Keenan, N. L., Anderson, L. A., \& LaCroix, A. Z. (2002). Use of alternative therapies for menopause symptoms: Results of a population-based survey. Obstetrics \& Gynecology, 100(1), 18-25.

Shih, S., Lew-Ting, C., Chang, H., \& Kuo, K. N. (2008). Insurance covered and noncovered complementary and alternative medicine utilization among adults in Taiwan. Social Science \& Medicine, 67(7), 1183-1189.

Stanford, E. (2001). China. Countries and Their Cultures. The Gale Group. Inc. Retrieved on February 24, 2009 from http://www.encyclopedia.com/doc/16i2340170053.htm

Su, D., Li, L., \& Pagán, J. (2008). Acculturation and the use of complementary and alternative medicine. Social Science \& Medicine, 66(2), 439-453.

Tsai, P. (2007). Use of complementary and alternative medicine by Chinese American women: Herbs and health care resources. University of Illinois at Chicago, Health Sciences Center), 113 p. (UMI Order AAI3294645.)

University of Maryland Medical Center (2009a). American ginseng. Retrieved on April 10, 2009 from http://www.umm.edu/altmed/articles/american-ginseng$\underline{000248 . h t m}$

University of Maryland Medical Center (2009b). Dong quai. Retrieved on April 10, 2009 from http://www.umm.edu/altmed/articles/dong-quai-000238.htm 
Upchurch, D. M., Chyu, L., Greendale, G. A., Utts, J., Bair, Y. A., Zhang, G., et al. (2007). Complementary and alternative medicine use among American women: Findings from the national health interview survey, 2002. Journal of Women's Health (15409996), 16(1), 102-113.

van der Sluijs, C. P., Bensoussan, A., Liyanage, L., \& Shah, S. (2007). Women's health during mid-life survey: The use of complementary and alternative medicine by symptomatic women transitioning through menopause in Sydney. Menopause (New York, N.Y.), 14(3 Pt 1), 397-403.

Yan, F. F., Liu, Y., Liu, Y. F., \& Zhao, Y. X. (2008). Herba epimedii water extract elevates estrogen level and improves lipid metabolism in postmenopausal women. Phytotherapy Research: PTR, 22(9), 1224-1228. 


\author{
Author Note \\ Rebecca Kwai-Ying Chung, Chia-Ling Mao and Karen Ketner, School of Nursing,
} San Jose State University.

We thank the Study of Women's Health Across the Nation (SWAN) for allowing us to use their CAM and women's health questionnaires. We also appreciate Professor Ellen B. Gold, professor and chair, Department of Public Health Science, UC Davis School of Medicine, for helping us to obtain permission to use the SWAN questionnaires. Additionally, we are also grateful to Professor Donna Stewart, Professor of the University of Toronto, for granting us the permission to use her acculturation questionnaire.

Correspondence concerning this article should be addressed to Rebecca KwaiYing Chung, E-mail: _ Chia-Ling Mao, School of Nursing, San Jose State University, San Jose, CA 95192. E-mail or Karen Ketner. School of Nursing. San Jose State University. San Jose. C 195192 . I:-mail: 
Table 1

Demographic Data

\begin{tabular}{|c|c|c|c|}
\hline & & Number & Percentage \\
\hline Total number of subjects & & 50 & 100 \\
\hline \multicolumn{4}{|l|}{ Age } \\
\hline & $46-50$ & 3 & 6 \\
\hline & $51-55$ & 10 & 20 \\
\hline & $56-60$ & 22 & 44 \\
\hline & Over 60 & 15 & 30 \\
\hline \multicolumn{4}{|l|}{ Place of birth } \\
\hline & China & 19 & 38 \\
\hline & Hong Kong & 18 & 36 \\
\hline & Taiwan & 5 & 10 \\
\hline & Malaysia & 3 & 6 \\
\hline & Not answered & 5 & 10 \\
\hline \multicolumn{4}{|l|}{ Year of stay in the USA } \\
\hline & $0-5$ years & 2 & 4 \\
\hline & $6-10$ years & 4 & 8 \\
\hline & $11-15$ years & 6 & 12 \\
\hline & $16-20$ years & 9 & 18 \\
\hline & Over 20 years & 27 & 54 \\
\hline & Not answered & 2 & 4 \\
\hline
\end{tabular}


CAM use among Chinese-American women 27

$\begin{array}{lll}\text { Yes } & 19 & 38 \\ \text { No } & 31 & 62\end{array}$

Menopausal status

$\begin{array}{rcc}\text { Premenopausal } & 8 & 16 \\ \text { Perimenopausal } & 9 & 18 \\ \text { Menopausal } & 33 & 66\end{array}$

Symptomatic women

$\begin{array}{rcc}\text { Premenopause }(\mathrm{n}=8) & 2 & 25 \\ \text { Perimenopause }(\mathrm{n}=9) & 5 & 55.6 \\ \text { Menopausal }(\mathrm{n}=33) & 16 & 48.5\end{array}$

Types of Symptoms

$\begin{array}{rcc}\text { Vasomotor Symptoms only } & 16 & 70 \% \\ \text { Somatic Symptoms only } & 3 & 13 \% \\ \text { Psychological symptoms only } & 0 & 0 \% \\ \text { Vasomotor and Psychological } & 1 & 4 \% \\ \text { symptoms } & & \\ \text { Vasomotor, somatic symptoms and } & 3 & 13 \% \\ \text { psychological symptoms } & & \end{array}$

Symptoms in different menopausal status

Vasomotor Symptoms

$\begin{array}{rcc}\text { Premenopause } & 1 & 14.3 \\ \text { Perimenopause } & 6 & 66.7 \\ \text { Menopausal } & 12 & 35.3\end{array}$


CAM use among Chinese-American women 28

\begin{tabular}{lccc}
\hline Somatic Symptoms & & & \\
& Premenopause & 1 & 12.5 \\
& Perimenopause & 0 & 0 \\
& Menopausal & 6 & 17.6 \\
\hline Psychological Symptoms & Premenopause & 0 & 0 \\
& Perimenopause & 0 & 0 \\
\hline Acculturation Levels & Menopausal & 3 & 8.8 \\
\hline & Level 1 & 12 & 24 \\
\hline & Level 2 & 32 & 64 \\
\hline & 6 & 6 & 12 \\
\hline
\end{tabular}


CAM use among Chinese-American women 29

Table 2

Menopausal Symptoms among Women of Different Menopausal Status

\begin{tabular}{lccc}
\hline Symptoms & Symptomatic & Symptomatic & Symptomatic \\
& Premenopausal & Perimenopausal & Menopausal \\
& Women $(\mathrm{N}=2)$ & Women $(\mathrm{N}=5)$ & Women $(\mathrm{N}=16)$ \\
& $\mathrm{n}(\%)$ & $\mathrm{n}(\%)$ & $\mathrm{n}(\%)$ \\
\hline Vasomotor Symptoms only & $1(50)$ & $5(100)$ & $11(68.75)$ \\
Somatic Symptoms only & $1(50)$ & 0 & $3(18.75)$ \\
Psychological symptoms only & 0 & 0 & 0 \\
Vasomotor and Psychological & 0 & 0 & $1(6.25)$ \\
symptoms & & 0 & $2(12.5)$ \\
Vasomotor, somatic symptoms & 0 & &
\end{tabular}


Table 3

CAM Use

\begin{tabular}{lccc}
\hline & $\mathrm{N}$ & $\%$ \\
\hline Use multiple types of CAM & 41 & 95 \\
Use single type of CAM & & 2 & 5 \\
\hline Major Types of CAM use & Nutritional remedies & 39 & $50.70 \%$ \\
& Herbal remedies & 32 & $74.42 \%$ \\
& Physical methods & 25 & $58.14 \%$ \\
& Psychological methods & 22 & $51.16 \%$ \\
\hline
\end{tabular}

Nutritional remedies

$\begin{array}{rr}\text { Calcium } & 30 \\ \text { Multivitamin } & 25 \\ \text { Vitamin C } & 10 \\ \text { Vitamin E } & 10 \\ \text { Vitamin D } & 10 \\ \text { Vegetarian Diet } & 6 \\ \text { Vitamin A } & 5 \\ \text { Vitamin B } & 5 \\ \text { Magnesium } & 4 \\ \text { Zinc } & 3 \\ \text { Other Vitamin } & 2 \\ \text { Megavitamin therapy } & 2\end{array}$


CAM use among Chinese-American women 31

$\begin{array}{cc}\text { Boron } & 1 \\ \text { Copper } & 1\end{array}$

Other mineral $\quad 1$

Glucozamine $\quad 1$

Omega-3 1

Herbal remedies

\begin{tabular}{|c|c|}
\hline American ginseng & 23 \\
\hline Dong quai & 10 \\
\hline Chuan Xiang & 9 \\
\hline Fu Ling & 8 \\
\hline Ginseng & 7 \\
\hline He Shou Wu & 6 \\
\hline Other Chinese herbs & 5 \\
\hline Siberian ginseng & 2 \\
\hline Chamomile & 2 \\
\hline Motherwort & 2 \\
\hline Bee Pollen & 2 \\
\hline Black cohosh & 1 \\
\hline Evening Primrose & 1 \\
\hline Ze Xie & 1 \\
\hline Other herbs & 1 \\
\hline Chinese patent formula & 1 \\
\hline Promensil & 1 \\
\hline
\end{tabular}


Physical methods

\begin{tabular}{|c|c|c|c|}
\hline & Massage & 10 & \\
\hline & Bodywork & 10 & \\
\hline & Acupressure & 9 & \\
\hline & Tai Chi & 9 & \\
\hline & Aerobics & 9 & \\
\hline & Yoga & 6 & \\
\hline & Chi Kong & 4 & \\
\hline Psychological Methods & & & \\
\hline & Prayer & 20 & \\
\hline & Attend a prayer group & 11 & \\
\hline & Relaxation technique & 6 & \\
\hline & Attend women's health group & 4 & \\
\hline & Hypnosis & 4 & \\
\hline & Others & 3 & \\
\hline & Meditation & 2 & \\
\hline & Aromatherapy & 1 & \\
\hline & Self help group & 1 & \\
\hline & Visualization / imagery & 1 & \\
\hline Reasons for using CAM & & & \\
\hline & General health maintenance & 31 & $72.09 \%$ \\
\hline & Women's health & 4 & $9.30 \%$ \\
\hline & Others & 2 & $4.65 \%$ \\
\hline
\end{tabular}


-

.

8

(w)

CAM use among Chinese-American women 33

\begin{tabular}{|c|c|c|}
\hline Menopausal symptoms & 1 & $2.33 \%$ \\
\hline Menstrual period symptoms & 1 & $2.33 \%$ \\
\hline Regulation of menstrual periods & 0 & $0.00 \%$ \\
\hline Missing data & 4 & $9.30 \%$ \\
\hline
\end{tabular}


3

Table 4

Acculturation and CAM Use

\begin{tabular}{|c|c|c|c|}
\hline Acculturation score & $\begin{array}{c}\text { Women attained this } \\
\text { score (n) }\end{array}$ & $\begin{array}{l}\text { CAM user } \\
\text { (n) }\end{array}$ & $\begin{array}{c}\text { CAM user } \\
(\%)\end{array}$ \\
\hline 8 & 4 & 3 & 75 \\
\hline 9 & 3 & 3 & 100 \\
\hline 10 & 5 & 4 & 80 \\
\hline 11 & 6 & 6 & 100 \\
\hline 12 & 8 & 7 & 87.5 \\
\hline 13 & 12 & 11 & 91.7 \\
\hline 14 & 3 & 2 & 66.7 \\
\hline 15 & 4 & 2 & 50 \\
\hline 16 & 3 & 3 & 100 \\
\hline 17 & 2 & 2 & 100 \\
\hline
\end{tabular}




\section{atst}

-

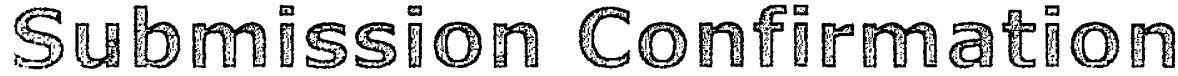

Wednesday, May 13, 2009 10:43 PM

"Social Science \& Medicine"

Dear Kwai Ying Chung,

Your submission entitled "The use of complementary and alternative medicine for menopausal symptoms among Chinese-American women." has been received by Social Science \& Medicine

You will be able to check on the progress of your paper by logging on to Elsevier Editorial Systems as an author.

Please go to 1 and use the 'log in' link at the top of the page.

Your manuscript will be given a reference number once an Editor has been assigned.

Whank you for submitting your work to this journal.

Kind regards,

Social Science \& Medicine 